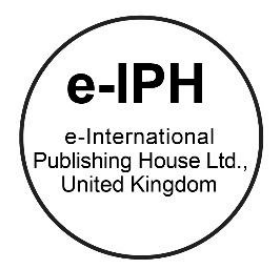

\title{
Understanding Wayfinding Experience of Hospital Visitor through Tours and Maps Analysis
}

\author{
Triandriani Mustikawati, Yandi Andri Yatmo, Paramita Atmodiwirjo \\ Department of Architecture, Faculty of Engineering, \\ Universitas Indonesia, Kampus Baru UI, Depok 16424, Indonesia \\ anisajid@gmail.com, triandriani.mustikawati@ui.ac.id \\ Tel:+62 81909911903
}

\begin{abstract}
This paper proposes a spatial narrative approach in understanding the wayfinding spatial experience of hospital visitors in a building environment. Narrative actions involved in wayfinding journeys are explored and analysed using tours and maps reading (de Certeau, 1984) as analysis tools. The study aims at gaining an understanding of how wayfinding spatial experience of visitors is organized. This study reveals that wayfinding consists of both itinerary and spatial knowledge that always relate to and influence each other. Understanding hospital visitors' wayfinding spatial experience comprehensively can expand our knowledge for designing a supportive healthcare facility's environment.
\end{abstract}

Keywords: wayfinding; spatial experience; tours and maps; narrative.

eISSN: 2398-4287@ 2017. The Authors. Published for AMER ABRA by e-International Publishing House, Ltd., UK. This is an open access article under the CC BYNCND license (http://creativecommons.org/licenses/by-nc-nd/4.0/). Peer-review under responsibility of AMER (Association of Malaysian Environment-Behaviour Researchers), ABRA (Association of Behavioural Researchers on Asians) and cE-Bs (Centre for Environment-Behaviour Studies), Faculty of Architecture, Planning \& Surveying, Universiti Teknologi MARA, Malaysia.

https://doi.org/10.21834/e-bpj.v2i6.992

\subsection{Introduction}

This paper discusses visitor's wayfinding in a hospital environment. Hospitals are the environment that usually has large and complex layout where a problem of finding one's way often occur, especially for patients and visitors who do not visit them frequently. The problem of wayfinding in a hospital can give many disadvantages for patients and visitors as the hospital users. Getting lost or being disoriented can cause anxiety and bring them in a stressful situation that may impact on their health condition. Wayfinding difficulty may also lead to the delay of obtaining medical treatment. For that reason, wayfinding has become an important factor in hospital design. It is one of the aspects that support hospital users' efficiency, safety and well-being (Carpman and Grant, 2016). Wayfinding becomes one of the parameters to the level of spatial quality of the healthcare facilities which affects the quality of service of the facilities (Haron et al., 2012, Samah et al., 2013).

Wayfinding had been long known as a process that involved spatial knowledge and cognition. The studies based on this theoretical lens had revealed different strategies and supporting elements that people use to help them memorise routes and places. Wayfinding had also been considered as a process that involved decision making, made at decision points. The studies from this point of view provided information about the different level of wayfinding task and type of decision points. All of these studies discussed wayfinding as a process that involved the interaction between human-mind and space. There is still limited knowledge that discusses how the process of wayfinding also involves the interaction between human-body and space.

This paper discusses the interaction between human-body and space during wayfinding, by considering wayfinding as a spatial experience. Spatial experience refers to how someone moves and relates to the surrounding space (Tuan, 1977). In this paper,

eISSN: 2398-4287C 2017. The Authors. Published for AMER ABRA by e-International Publishing House, Ltd., UK. This is an open access article under the CC BYNCND license (http://creativecommons.org/licenses/by-nc-nd/4.0/). Peer-review under responsibility of AMER (Association of Malaysian Environment-Behaviour Researchers), ABRA (Association of Behavioural Researchers on Asians) and cE-Bs (Centre for Environment-Behaviour Studies), Faculty of Architecture, Planning \& Surveying, Universiti Teknologi MARA, Malaysia.

https://doi.org/10.21834/e-bpj.v2i6.992 
wayfinding of a hospital visitor will be seen as a journey that consists of serial movements from place to place. The paper aims at understanding of how spatial experience of a visitor is formed and organised during this place-to-place movement.

Analysing spatial experience had been a challenge for many researchers studying on human and space relation. One of the analysis tools proposed by de Certeau (1984) looking at the spatial experience as consisted of two basic elements, namely 'tours' and 'maps'. This approach had been used in some studies, to reveal the process of place inhabitation (Lozanovska, 2002), the animated place identity of a heritage environment (Guano, 2003) and to investigate movement connectivity in therapy activities (Yatmo et al., 2017). Tours and maps reading is used in this paper to study the process of how space is experienced during wayfinding journey. The objectives of this study are:

1. to reveal a spatial experience during wayfinding journey of a visitor by creating narrative actions of the journey.

2. to identify operations involved in the spatial experience by tours and maps analysis

3. to find out on how the operations are related and organised wayfinding spatial experience.

\subsection{Literature Review}

\subsection{Wayfinding in previous research}

Wayfinding had been widely studied within environmental psychology, geography, and environmental communication domain. Some studies put emphasise on internal factors; the process worked 'inside' human mind. These studies discussed more on the use and construction of spatial knowledge (Lu and Bozovic-Stamenovic, 2009; Ohtsu, 2017). Other studies emphasise on how external factors contribute to wayfinding. These external factors include spatial structure (Holscher, C. et al., 2009), environmental cues (Hund and Gill, 2014; Pati, D. et al., 2015) and graphic communication (Li, P. et al., 2010; Zheng, M., 2012; Lee, S. et al., 2014).

Lack of studies discussed the 'in between' process of wayfinding, the link between internal and external factors: on how human interacts with space while he finds his way. This paper will discuss indoor wayfinding through this perspective. Wayfinding will be observed as a human spatial practice that produces spatial experience within an indoor hospital environment.

\subsection{Wayfinding as a spatial experience: directed movement from place to place}

Aside from spatial knowledge and environmental factors that become supporting tools, wayfinding is also involved spatial experience. Looking at wayfinding as a spatial experience will include the act of moving from place to place. Movement refers to a shift of body's location between one point to another within space. Tuan (1977) argued that movement was a way of how a person experiences the space he was inside. He explained:

"Space is experienced directly as having room in which to move. Moreover, by shifting from one place to another, a person acquires a sense of direction".(p.12)

The movement involved in wayfinding is not of any kind but a directed movement. As a goal-oriented process, the activity involved in wayfinding has the objective of reaching the destinations. All of the place to place movements conducted in wayfinding is directed to reach that goal. What direct these movements are cues obtained from the environment by the mechanism of visual cue-searching that involved visual reading (Mustikawati et al., 2017). This paper will elaborate how people move from place to place involved in visitors' wayfinding experience.

Some studies had focused movement involved in wayfinding. Bohari, et al. (2016) study movement in assessing pedestrian wayfinding that occurred within the transit train station. This study focused on the pattern and time-related to the movement. An unobtrusive observation and software-based simulation were carried out on crowd movement. Hashim and Said (2013) in studying outdoor wayfinding, examined visitor movement behaviour. The issue on how a visitor interacts with architectural space was raised using a quantitative survey method. Although these studies had discussed movement-related wayfinding, they had not discussed movement as series of operations of how someone experiences space. What movement operations involved in wayfinding as an individual shifts from one place to another will be discussed in this paper.

\subsection{Assessing spatial experience: tours and maps analysis}

In this paper, we use spatial narrative approach by applying tours and maps analysis based on de Certeau (1984). De Certeau had the idea of approaching spatial experience through a narrative lens. He argued that the spatial stories that organized spatial experience should be analyzed by looking at the narrative actions which constructed the stories. Tours and maps are two elementary elements of practices organizing space. They knit spatial stories of a spatial experience. In this paper, we relate the spatial experience of visitors with the journey that visitors experienced in moving from place to place to find their destinations.

The first element that constructs the structure of the stories, according to de Certeau, is the tour. The concept of "tour" can be understood as the itinerary of a journey, the element that describes the spatializing action. It contained movement prescriptions that consisted of a discursive series of operations. Tour organized movement and was dynamic. "Turn left and go upstairs" and "go straight through this corridor" are the examples of "tour."

The map is the second element of the structure. Maps refer to a tableau that marks out the citation of places. It consisted of an order of places and described a projection of totalizing observation in relation with seeing that define location of objects. The map was 
static since it captured one condition at one specific point. The example of the maps are "on the front wall there is a sign of ...." and "there are some examining rooms on the left side."

In this paper, we argue that tours and maps have the potential to be used in analyzing a wayfinding spatial experience of a visitor. We found some studies discussed tours and maps approach to explore a human spatial experience. Lozanovska (2002) raised an issue about the problem of everyday representation. She argued that representing a place was not just simply by drawing a plan of geographical territories that produce a determinate spatial configuration. Lozanovska put importance on revealing the process of inhabitation behind the spatial configuration. She also suggested that the process of inhabitation had something to do with visibility and movement. Maps as the trace of dot and line have the potential of bringing into visibility what is invisible (p.144). Visibility articulated map as trajectories of desire. The representation of place was also entangled with the movement between objects in space. Movement showed how human body occupies the space.

Another study by Guano (2003) also used the tours and maps approach to explore a spatial experience within La Boca, a heritage place. By moving through the neighborhood and creating a narrative story, Guano pointed out that a place which filled with local imageries like La Boca could have a dominant map. The tour on the other hand, as the movement prescription, had the potential of controlling the steps of which place should be visited and which one should be avoided. The attempts of using tour and map as practical spatial narratives finally had created an animated place identity.

If Lozanovska (2002) and Guano (2003) used the tours and maps analysis to see spatial experience in outdoor environment, the study by Yatmo et al. (2017) used this analysis to explore a spatial experience within an indoor environment. The tour and map analysis were used to investigate movement connectivity on autistic children spatial experience during their therapy activities. Yatmo et al. conducted more thorough analysis by considering the whole experience as a sensory tour that consisted of a discursive series of operations. They looked into the relationship between the operations and space. This study revealed that space and its surrounding objects could trigger different operations to occur. The four types of operation that occurred during the tour conformed to what de Certeau (1984) explained as the describers of the map, namely: effect, limit, possibility, and obligation. The operation of effect would occur as a response to the order of objects, while a given in space could become a limit of the operation and restrict some movements. The possibility took place when there was/were an object(s) of space that could enable a certain operation to occur. The operation as obligation would happen if the surrounding object (s) could force the body action. The result of the study showed the relation between certain spatial properties and movements.

Our study considers wayfinding as a spatial journey. Every journey is elaborated into the elements of movement (tour) and object of seeing (map). Through tour and map reading this paper explores the operations involved in the journey to develop an understanding of wayfinding spatial experience.

\subsection{Method}

This paper is based on a study conducted in an outpatient area in a General Hospital located in Malang, Indonesia. The outpatient area is on the located first and second floor of the main hospital building and consisted of several clinics (figure 1).

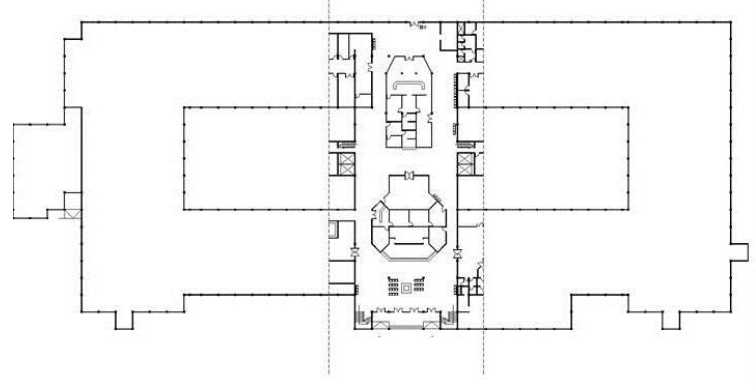

(a)

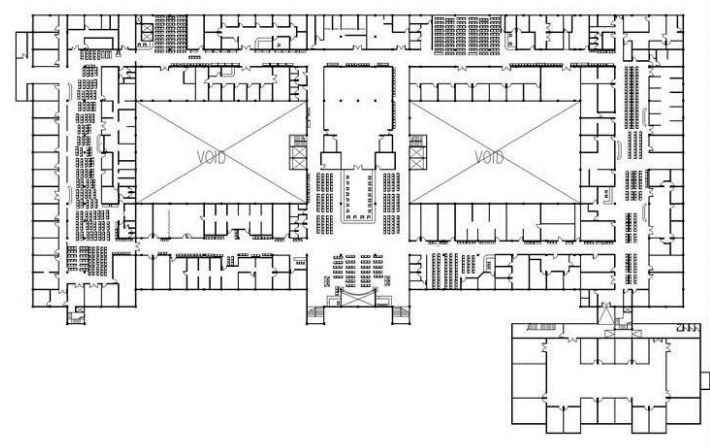

(b)

Fig. 1 The layout of research setting (a) first floor (b) second floor

In this study, the wayfinding experience of visitors was obtained from a series of observations of participants conducting wayfinding task. There were ten participants involved in this study, four females and six males, with age, ranged between 23 and 50 years. All of the participants had not visited the hospital more than once in the 12 months before this study, therefore were assumed as new visitors.

Every participant was asked to do a wayfinding journey. The journey started from the main entrance at the first floor to several destinations, simulating the journey of a new patient taking the hospital treatment procedure. During the journey, participants were not allowed to ask for direction to other people and had to depend only on the cues from their surrounding. Participants also had to do the verbal protocol, saying aloud what they see, what they look for, and what action they took during the journey. During the journey, 
observations were conducted by a researcher who accompanied the participant. This walking-with observation purposed on gave more insight of the ongoing journey. All of the journeys were documented in videos by research assistants. The verbal protocols were also recorded and translated into transcripts.

This study recorded the total of 40 wayfinding journeys of participants. For this paper, an analysis was carried out to one of wayfinding journey. The journey included the search for a route from the main entrance on the first floor to the outpatient area on the second floor.

The primary material for analysis consisted of the observation videos and the verbal protocol transcripts. The video and the transcripts were translated into narrative actions containing every sequence of action taken during the journey. From these materials, the tours and maps analysis was conducted to explore the spatial experience during the journey. The tours and maps elements were identified manually from the describer (de Certeau, 1984). The elements of a tour were any phrase or sentence from the narrative that gives the prescription of movement of the journey, while the elements of a map were phrase or sentence that describe any object or condition seen by the visitors.

The method of this study had some limitations acknowledged. They are:

- Despite the rich data source obtained from the observation video and verbal protocol transcripts, the analysis only used one journey of a participant. The study with more amount of cases could establish more reliable result.

- The identification of tour and maps components were conducted manually that it could be very subjective. The development of an analysis software could save the time of analysis and provide a more objective result.

\title{
4.0 Findings
}

\subsection{The Narrative actions and scenes of a wayfinding journey}

To reveal the spatial experience during wayfinding journey, narrative actions of the journey were structured based on the video, verbal protocol and behaviour map recorded. This narrative actions consisted of the sequence of actions, space and time during the wayfinding journey telling us on how a visitor operates and move in space. For this paper, an example analysis of a journey from one participant was analysed. The journey included the search for a route from the main entrance to the outpatient area. The following paragraph is the narrative actions of the participant's (P1) journey.

\begin{abstract}
P1 began the journey from the main entrance of the main building. She looked at the main entrance door and saying "I enter the left door of main entrance." Then she walked through the door entering the first-floor lobby. A few steps after passing the entrance, she stopped. She looked to her left and right side, then said: "I'm looking for the outpatient area." She turned her body to the left, paused for a moment, then looked at the wall in front of her and said: "there are a BPJS sign and also stairs." Then she walked toward the stairs while kept her eyes on them. She said, "I turn left and walk up the stairs." She walked up the stairs and looked ahead. On the landing, she turned to the next stairs and looked upward. On the last few steps she walked up and looked ahead, then she said: "I have arrived at the second floor." She walked slowly forward while turning her head and looking to the right, where she saw people on the copy service. After some steps forward, she saw the hanging sign at a distance, stopped for a moment to read the sign. As she turned her head to the right, she walked slowly forward and paused for a moment. And after looking at her right side, she said: "It seems that I am not in the outpatient area yet." Then she walked slowly forward and stopped. She saw the hanging sign on her front left, read the content then she said, "It seems that I am already in the outpatient area since the sign said so."
\end{abstract}

The above paragraph shows the sequences of movements and operations of a wayfinding journey. The exploration of the narratives was conducted by breaking them into scenes. From the narrative in each scene, we identified the detailed operations that involved in the journey. Table 1 shows the scenes of the journey that completed with the setting of the scene and narrative texts. The detailed operations of each scene are marked in bold texts. 
Table 1. The sequential scenes from a wayfinding journey

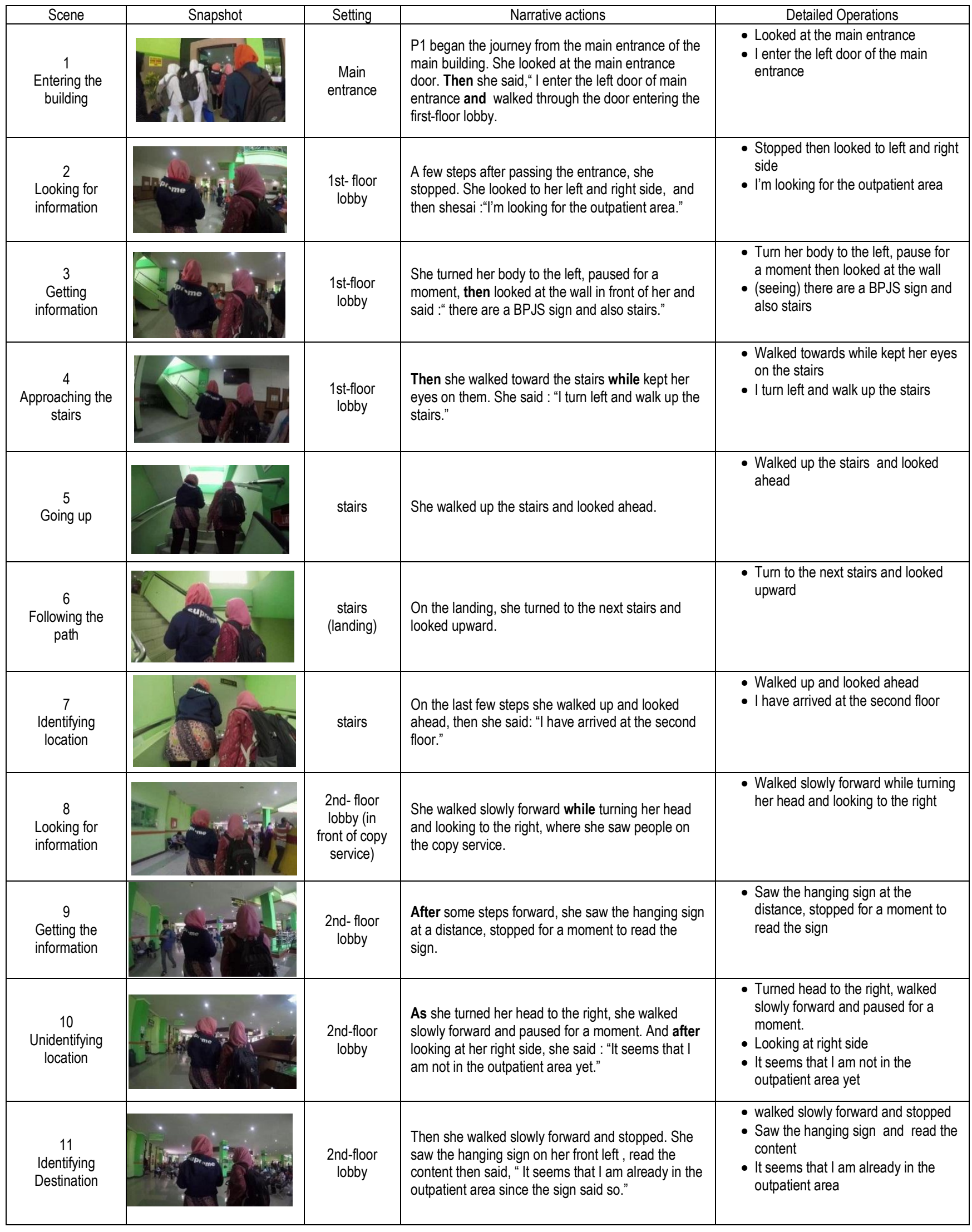

The journey consists of 11 scenes. Each scene is determined by the different micro event that happened in the related time . For example, the first scene was about entering the building, since it consisted of operations that showed how the visitor entered the 
building. The whole scene showed how the visitor changed position and moved from one location to another. Figure 3 shows the sequence of scenes and the setting where they took place.

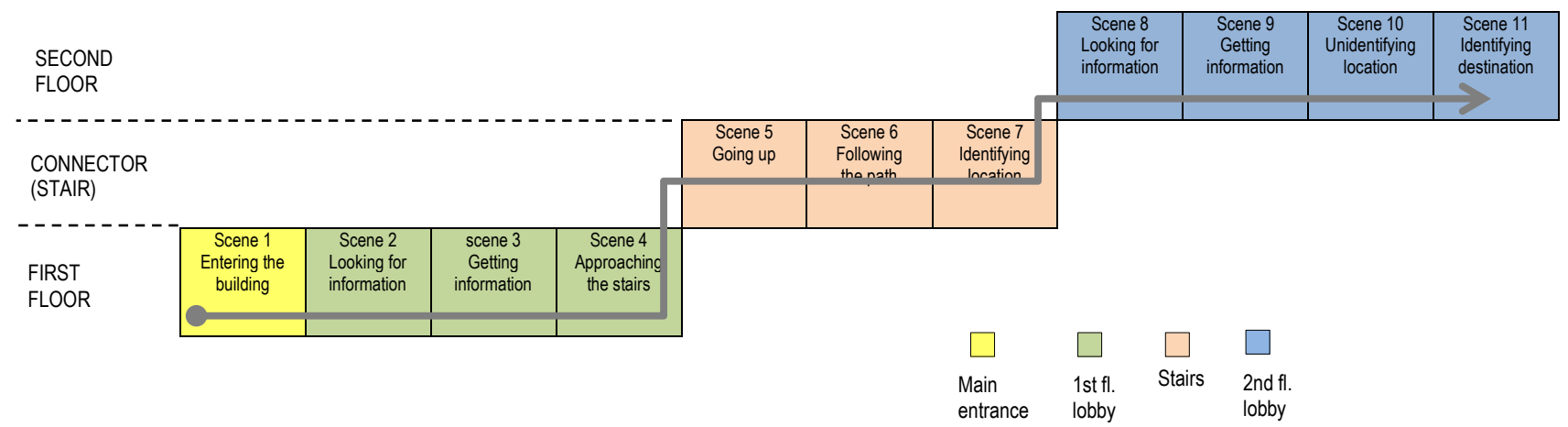

Figure 3. The sequence and setting of scenes

\subsection{The operation of tours and maps}

From the narrative actions, we have identified some detailed operations that appear in every scene in the journey. These operations were categorized into tours and maps component. The operations of tours included the detailed operation that prescribes movement of the journey, while the operations that relate to the object, condition or location based on "seeing" were considered as maps. Table 2 shows the tours and maps component of the journey.

Table 2. The detailed operations as tours and maps components

\begin{tabular}{|c|c|c|c|}
\hline SCENE & SETTING & Tours & Map \\
\hline $\begin{array}{c}3 \\
\text { Getting information } \\
\end{array}$ & 1st-floor lobby & Turn her body to the left, pause for a moment & $\begin{array}{l}\text { looked at the wall } \\
\text { (seeing) there are a BPJS sign and also stairs }\end{array}$ \\
\hline $\begin{array}{c}5 \\
\text { Going up }\end{array}$ & stairs & Walked up & looked ahead \\
\hline $\begin{array}{c}6 \\
\text { Following the path }\end{array}$ & stairs (landing) & Turn to the next stairs & looked upward \\
\hline $\begin{array}{c}9 \\
\text { Getting the information }\end{array}$ & 2nd-floor lobby & stopped for a moment & $\begin{array}{l}\text { Saw the hanging sign at the distance } \\
\text { Read the sign }\end{array}$ \\
\hline $\begin{array}{c}10 \\
\text { Unidentifying location }\end{array}$ & 2nd-floor lobby & $\begin{array}{l}\text { walked slowly forward, and paused for a } \\
\text { moment. }\end{array}$ & $\begin{array}{l}\text { Looking at right side } \\
\text { It seems that I am not in the outpatient area } \\
\text { yet }\end{array}$ \\
\hline $\begin{array}{c}11 \\
\text { Identifying Destination }\end{array}$ & 2nd-floor lobby & walked slowly forward and stopped & $\begin{array}{l}\text { Saw the hanging sign and read the content } \\
\text { It seems that I am already in the outpatient } \\
\text { area }\end{array}$ \\
\hline
\end{tabular}


From the operation of tours and maps showed on the table shows, we composed a diagram that translates wayfinding journey into a sequence of tours and maps operations. The diagram can be seen in figure 4 .

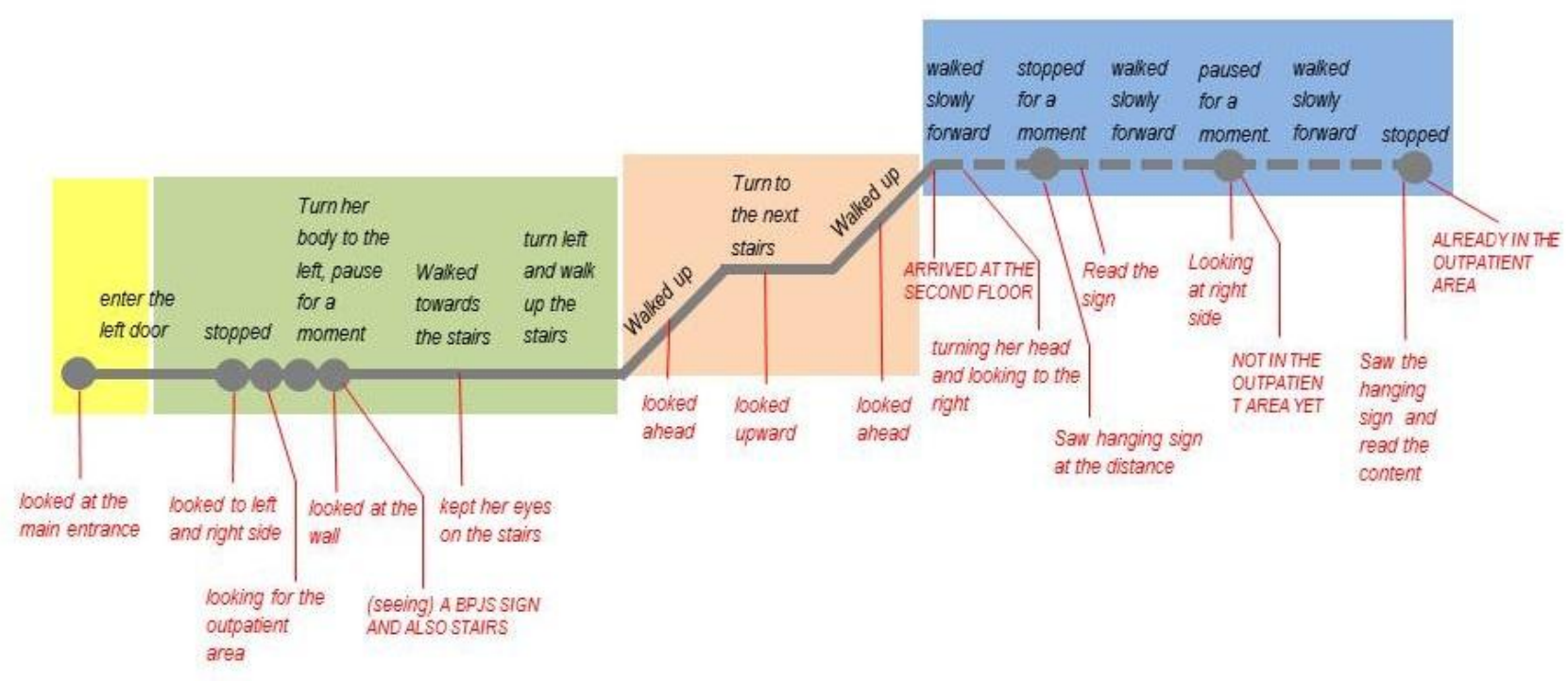

Figure 4. The sequence of tours and maps operations diagram

The diagram is a path showing the sequence of tours and maps operations. It consists of line and dots. The line represents the dynamic movement of the body,showing when the visitor walked. The continuous line shows the regular speed walk while dash line marks the slow speed walk. The dots mark the static position of the visitor or when she paused or stopped during the journey. The row of dots in the diagram represents a long stop. The map operations (in red text) are then put along the line according to the time when they took place. From the diagram, we can see how visitor moved from one setting to another during the journey and when they try to search for information to define space.

\subsection{The consecutive and parallel relation between operations}

The relation between the operations of tours and maps is explored by highlighting the conjunctions that exist between operation in the narrative actions. There are five conjunctions used: 'then',' after','while', 'as', and 'and'. From the conjunctions, we identified two types of relations between operation, those are consecutive relation and parallel relation.

The consecutive relation occurs when an operation is followed by another operation. This kind of relation is marked by the conjunctions 'then' and 'after". Table 3 shows the type of relation in consecutive relation between operation that occurred in the journey.

Table 3. The consecutive relation between operations

\begin{tabular}{ll}
\hline \multicolumn{1}{c}{ TYPE OF CONSECUTIVE RELATION } & \multicolumn{1}{c}{ EXAMPLE } \\
\hline Map followed by Tour & $\begin{array}{l}\text { She looked at the main entrance door . Then she said "I enter the left door of main } \\
\text { entrance" }\end{array}$ \\
\hline Tour followed by Map & After some steps forward, she saw the hanging sign at the distance \\
\hline Tour followed by Tour & A few steps after passing the entrance, she stopped \\
\hline Map followed by Map & $\begin{array}{l}\text { She saw the hanging sign on her front left , read the content then said, "It seems that I } \\
\text { am already in the outpatient area }\end{array}$ \\
\hline
\end{tabular}

The parallel relation occured when two or more operations happened at the same time. This relation is shown by the conjunction 'while', 'as' or 'and'. The parallel relation between operation can be seen in Table 4. 
Table 3. The Parallel relation between operations

\begin{tabular}{|c|c|}
\hline TYPE OF PARALLEL RELATION & EXAMPLE \\
\hline Tour parallel with Map & $\begin{array}{l}\text { she walked toward the stairs while kept her eyes on them } \\
\text { As she turned her head to the right, she walked slowly forward }\end{array}$ \\
\hline Map parallel with Map & looked at the wall in front of her and said " there are a BPJS sign and also stairs. \\
\hline
\end{tabular}

\subsection{Discussion}

The findings show a narrative approach to explore a wayfinding journey. By delivering a wayfinding journey in narrative actions, we can explore the spatial experience by looking at the sequence of movements and other operations happened during the journey. The narrative approach enables us to share what subject experience in space during the journey such as viewpoints and earpoints (Myers, 2010). This study shows that narrative can reveal not only the viewpoints or what the subject sees but also how she got that view. The narrative also shows how the body shift position or change orientation in the process of searching. All of the movements involved are the response to what happened in the surrounding space. By moving and respond to space, a sense of direction is gained (Tuan, 1977).

The findings also revealed the scenes or micro events that composed the narrative. Each scene consists of operations and took place in a setting. Operations happened in a specific setting as a response to different spatial properties provided by the setting (Yatmo, 2017). This study only showed that a setting could have one or more scene(s), but had not explored the spatial properties of the setting in relation to the operations.

The tours and map analysis of the journey show that the wayfinding journey consists of operation of tours and operation of maps. The operation of tours involved 'walk and stop' movement, composing a 'walk and stop' path. The existence of some stopping points during the movement path conform with what Passini (1992) called as decision points. The movement had not been done unpurposely, since wayfinding is a goal-directed process (Miller, 1992). It is the map that guide of the movement by marking out or becoming 'the citation of the place' (de Certeau, 1984). The acts of marking out were conducted through some 'seeing' operations that involved visual gesture (e.g. looked at the wall, kept the eyes on the stairs, etc.). The mechanism of visual cue-searching involving the visual gestures is called visual reading (Mustikawati et al., 2017). During the journey, the participant observes her surrounding, looking for visual cues. Relate to the spatial quality of the environment; the visual reading might be conducted only if the environment provides a sufficient visual field. The sufficient visual field enables the visitor to turn the head to the left and right side of the body.

The study also showed that every operation related to other operation. The relation could happened parallelly or consecutively. De Certeau (1984) had an explanation about the consecutive relation between the operation of tours and maps. According to de Certeau, the operation of tour could occur first to enable the occurrence of map operation. In this study, the example of this relation happened when the subject concluded that she had the arrived at the second floor after she walked up and look ahead to the last few steps of the stairs. Furthermore, de Certeau explained that the operation of map could also become a trigger for a tour operation. The example of this relation was when the subject enters the left door of the main entrance after she looked at the main entrance door. The door as the object (of a map) triggers the movement of entering the building (tour). By looking at the relation between every operation, we can see how a wayfinding journey was organized.

\subsection{Conclusion}

Exploring a visitor's wayfinding through a narrative approach enables further understanding on wayfinding as a spatial experience. The narrative actions contain sequences of movement operations carried out by a visitor in finding a destination within a hospital environment. By presenting a wayfinding spatial experience in narrative actions, It is possible to look deeper into the process of searching destination by breaking it into scenes consisting of operations.

This paper also showed the potential of tours and maps as a tool for analyzing a wayfinding journey. This analysis reveals that a wayfinding journey consists of itinerary and spatial knowledge. The itinerary creates a 'walk and 'stop' path obtained from the tour components. The spatial knowledge was obtained from the maps component that marked places in the path. The tours and maps analysis also enables further development of wayfinding representation that can illustrate how visitor experiences space through sequence of movements.

However, this paper was based on only one case of visitor journey. Further study with more case of analysis should be conducted to explore more about the relation between wayfinding journey and the surrounding space, and how the relation can occur. Through tour and maps analysis, it becomes possible to obtain a better understanding of wayfinding spatial experience and its relation to the quality of space.

\section{Acknowledgements}

This paper is part of Triandriani Mustikawati's doctoral research. This publication was funded by Hibah Publikasi Terindeks Tugas Akhir (PITTA) Grant from Universitas Indonesia. The author would like to express much gratitude to all who have contributed to this 
paper, especially the management of Rumah Sakit Saiful Anwar, Malang, Indonesia, and all of our colleagues in the Department of Architecture, Faculty of Engineering, Universitas Indonesia.

\section{References}

Bohari, Z. A., Bachok, S., \& Osman, M. M. (2016). Simulating the Pedestrian Movement in the Public Transport Infrastructure. Procedia-Social and Behavioral Sciences, 222, 791-799.

Carpman, J. R., \& Grant, M. A. (2016). Design That Cares: Planning Health Facilities for Patients and Visitors (Vol. 142). John Wiley \& Sons.

de Certeau, M. (1984). The Practice of Everyday Life (S. Rendall, Trans.).

Guano, E. (2003). A Stroll Through La Boca: The Politics And Poetics Of Spatial Experience In A Buenos Aires Neighborhood. Space and Culture, 6(4), 356-376.

Haron, S. N., Hamida, M. Y., \& Talib, A. (2012). Towards Healthcare Service Quality: An Understanding Of The Usability Concept In Healthcare Design. ProcediaSocial and Behavioral Sciences, 42, 63-73.

Hashim, M. S., \& Said, I. (2013). Effectiveness Of Wayfinding Towards Spatial Space And Human Behavior In Theme Park. Procedia-Social and Behavioral Sciences, 85, 282-295

Hölscher, C., Büchner, S. J., Meilinger, T., \& Strube, G. (2009). Adaptivity Of Wayfinding Strategies In A Multi-Building Ensemble: The Effects Of Spatial Structure, Task Requirements, And Metric Information. Journal of Environmental Psychology, 29(2), 208-219.

Hund, A. M., \& Gill, D. M. (2014). What Constitutes Effective Wayfinding Directions: The Interactive Role Of Descriptive Cues And Memory Demands. Journal Of Environmental Psychology, 38, 217-224.

Lee, S., Dazkir, S. S., Paik, H. S., \& Coskun, A. (2014). Comprehensibility Of Universal Healthcare Symbols For Wayfinding In Healthcare Facilities. Applied Ergonomics, 45(4), 878-885.

Li, P. Y., Zheng, M. C., \& Hibino, H. (2010). Map Design in Subway Stations through Passengers' Wayfinding Behavior Perspective. Asian Journal of EnvironmentBehaviour Studies, 2(2), 105-115.

Lozanovska, M. (2002). Architectural Frontier/Spatial Story: The Problematic Of Representing The Everyday. Space and Culture, 5(2), $140-151$.

Lu, Y., \& Bozovic-Stamenovic, R. (2009). Cultural Perspective Of Wayfinding Behavior Exploring The Socio-Spatial Variable In Three Chinese Hospitals Case Studies. ArchNet-IJAR, 3(2).

Miller, H. J. (1992). Human wayfinding, environment-behaviour relationships, and artificial intelligence. Journal of planning literature, 7(2), 139-150.

Mustikawati, T., Yatmo, Y. A., \& Atmodiwirjo, P. (2017). Reading the Visual Environment: Wayfinding in Healthcare Facilities. Environment-Behaviour Proceedings Journal, 2(5), 169-175.

Myers, M. (2010). 'Walk With Me, Talk With Me'1: The Art Of Conversive Wayfinding. Visual Studies, 25(1), 59-68.

Ohtsu, K. (2017). Spatial Learning by Egocentric Updating during Wayfinding in A Real Middle-Scale Environment: Effects of differences in route planning and following. Journal of Environmental Psychology, 50, 51-59.

Pati, D., Harvey Jr, T. E., Willis, D. A., \& Pati, S. (2015). Identifying Elements of the Health Care Environment That Contribute to Wayfinding. HERD: Health Environments Research \& Design Journal, 8(3), 44-67.

Samah, Z. A., Ibrahim, N., \& Amir, J. S. (2013). Translating Quality Care Factors To Quality Space: Design Criteria For Outpatient Facility. Procedia-Social and Behavioral Sciences, 105, 265-272

Tuan, Y. F. (1977). Space And Place: The Perspective Of Experience. University of Minnesota Press.

Yatmo, Y. A., Atmodiwirjo, P., \& Paramita, K. D. (2017). Topological Reading of Movement Connectivity in Sensory Integration Space for Autistic Children. Space and Culture, 20(1), 24-41.

Zheng, M. C. (2012). Time Constraints In Emergencies Affecting The Use Of Information Signs In Wayfinding Behavior. Procedia-Social and Behavioral Sciences, 35, 440-448. 